\title{
Breakfast and fast food eating behavior in relation to socio-demographic differences among school adolescents in Sanandaj Province, Iran
}

\author{
Foad Alimoradi ${ }^{1}$, Parisa Jandaghi ${ }^{2}$, Adeleh Khodabakhshi ${ }^{3}$, Maryam Javadi ${ }^{4}$, Seyed Amir Hossein Zehni \\ Moghadam ${ }^{5}$
}

${ }^{1}$ M.Sc. of Nutrition, Department of Nutrition, Faculty of Health, Qazvin University of Medical Sciences, Qazvin, Iran

${ }^{2}$ M.Sc. of Nutrition, Department of Nutrition, Faculty of Health, Qazvin University of Medical Sciences, Qazvin, Iran

${ }^{3}$ M.Sc. of Clinical Nutrition, Department of Nutrition, Student Research Committee, Faculty of Nutrition and Food Technology, Shahid Beheshti University of Medical Science, Tehran, Iran

${ }^{4} \mathrm{Ph}$.D. of Nutrition, Associate Professor, Department of Nutrition, Faculty of Health, Qazvin University of Medical Sciences, Qazvin, Iran

${ }^{5}$ M.Sc. of Nutrition, Department of Nutrition, Faculty of Health, Qazvin University of Medical Sciences, Qazvin, Iran

Type of article: Original

\begin{abstract}
Introduction: Fast food consumption and skipping breakfast has been increasingly prevalent among high school adolescents in recent years. These unhealthy food habits are considered as risk factors of chronic diseases among adolescents and adults.

Aim: To determine the consumption amount of fast food, breakfast, and some associated factors in adolescents.

Methods: In this cross-sectional study in 2015, 553 adolescent students aged 14-18 years were randomly selected among high schools of Sanandaj, Iran. Demographic data and also consumption amount of fast food and breakfast in adolescents in addition to the related factors were studied. Data were collected using a researchermade questionnaire which its reliability and validity were measured by five experts and analyzed with SPSS-16 by Chi-square test and ANOVA.

Results: The results show that $69.8 \%$ of subjects consume fast food at least once a week. Fast food and breakfast consumption is related significantly to subjects' fathers' occupation respectively $(p=0.005),(p=0.006)$. Eating breakfast is significantly higher among boys than girls $(\mathrm{p}<0.001)$. There is also a significant relationship between adolescents' age and parents' education level, and adolescents' breakfast consumption respectively ( $\mathrm{p}=0.003$ ), $(p<0.001)$. The studied factors affecting adolescents' fast food consumption are: their own and their families and friends' interest and accompaniment, advertisement, close proximity of school and home to fast food stores.

Conclusion: The consumption of fast food is high among Iranian adolescents. It correlates significantly with variables including father's occupation and all of the associated factors. Breakfast consumption correlates significantly with adolescents' age and gender, as well as parents' occupation and educational level.
\end{abstract}

Keywords: Fast Food, Breakfast, Adolescents, Eating habits

\section{Introduction}

Healthy eating habits in childhood and adolescence meet nutritional needs, affect physical and mental development as well as future health, and prevent chronic diseases in adulthood $(1,2)$. Eating habits are formed during the teens and bad habits can have undesirable outcomes in adulthood (3). Several studies revealed inadequate dietary intakes, particularly among adolescents (4). Studies have investigated the food environment in residential neighborhoods,

\section{Corresponding author:}

Seyed Amir Hossein Zehni Moghadam, Department of Nutrition, Faculty of Health, Qazvin University of Medical Sciences, Qazvin, Iran. Tel: +98.9124705196, Fax: +98.2144728771, Email: Amir.moghadam4@gmail.com

Received: December 14, 2016, Accepted: March 19, 2017, Published: June 2017

iThenticate screening: March 02, 2017, English editing: May 10, 2017, Quality control: May 20, 2017

(C) 2017 The Authors. This is an open access article under the terms of the Creative Commons Attribution-NonCommercialNoDerivs License, which permits use and distribution in any medium, provided the original work is properly cited, the use is non-commercial and no modifications or adaptations are made. 
and researchers are increasingly alerting the population to the health risks of school food environments. In the USA, where the prevalence of childhood obesity is epidemic, policy makers are urgently working towards reforming the school food environment (5). Children and adolescents' bad eating habits include increased consumption of fast food and reduced breakfast consumption (6-8). The recent study showed that lack of having breakfast and increased consumption of fast food is associated with risk factors for metabolic syndrome among adolescents (9). According to a study in Sanandaj, the prevalence of abnormal BMI, particularly overweightness and obesity was high in adolescents. About one fourth of the adolescents had an abnormal BMI (4.9\% and 21.2\% lower and higher than normal range, respectively) (10). A study in Tehran found out 3\% of teenagers' poor diet and $74 \%$ of teenagers should improve compared with the recommended standard food pyramid (3). A study showed that $24 \%$ of boys and $20 \%$ of girls consume fast food more than 3 times a week, while in the present study, $9.9 \%$ of boys and $8.9 \%$ of girls had fast food more than 3 times a week (11). Fast food eating has become prevalent in many communities and such restaurants increased in number making this type of food easily available to everyone $(12,13)$. Some studies suggest that most consumers of fast foods are young people up to the age of 20 . Statistics reveal that around $40 \%$ of high school students eat fast food once or twice a month (7). Research shows that this type of food causes diabetes, obesity, and other chronic diseases (13). Breakfast is the most important meal of the day, playing a crucial role in maintaining children and adolescents' health (14). Despite the importance of breakfast, it has been largely ignored by a great number of young people from different countries, reportedly with the prevalence of $3 \%$ to $34 \%$. Studies in other countries also suggest a rising trend in adolescent's consumption of fast foods $(6,7)$. Given the increasing prevalence of bad eating habits and BMI abnormality among adolescents in Sanandaj, its connection with metabolic syndrome, and also the lack of similar studies carried out in Sanandaj, the present study was designed to determine the consumption of fast food and having breakfast among adolescents, living in Sanandaj, Iran.

\section{Material and Methods}

This cross-sectional study was carried out on 553 adolescents in the 14 to18 year age, in Sanandaj, in 2015. Five high schools were selected by random cluster method. A list of students in each school was prepared, from which, a sample set was randomly selected. All the members of the sample set entered the study, except for those with special diets. In the end, 553 students completed the study. Informed consents were obtained from all members of the sample set at the beginning of the study. A researcher-made questionnaire was the data collection tool and its reliability and validity were measured by five experts. Its reliability (internal consistency) was calculated 0.66 by Cronbach's alpha; and its validity being determined in terms of content \& face validity. This two-section questionnaire has 15 clear questions. In the first section, members of sample set's demographic and personal data (e.g. age, gender, members of sample set parents' education level and occupation) were collected. The second section contains questions related to the consumption of fast food and breakfast. Participants were also asked about the causes of their inclination to fast foods (adolescents' own interest, their family's interest, friends' effect, advertisement, close proximity of school and home to fast food store). Fast food and breakfast consumption was a self-report in the questionnaire. The frequency of breakfast and fast food consumption was measured per week: $1=$ Never/Week, $2=1-2 \mathrm{x} /$ Week, $3=3-4 \mathrm{x} /$ Week, $4=5 \leq \mathrm{x} /$ Week. The data were analyzed using SPSS version 16 (SPSS Inc., Chicago, IL, USA). Quantitative data were shown as mean \pm SD and frequency as $\mathrm{n}(\%)$. Based on the distribution of samples, Chi-square test was applied to measure the association between the qualitative variables (gender, parents' education and occupation) and fast food/breakfast consumption, and ANOVA was used for relation of the quantitative variable of age and breakfast/fast food consumption. $p$-value $\leq 0.05$ was considered significant.

\section{Results}

Based on the results from 553 participants in the study, $51.7 \%$ were male and $48.3 \%$ were female. The mean of age was $16.24 \pm 1.22$. Table 1 shows demographic data such as age, gender, parents' occupation and educational level, as well as their association with fast food/breakfast consumption in 4 columns showing the frequency of consumption. This study shows that $18.2 \%$ of subjects had breakfast 2 days a week or less. Breakfast consumption was significantly higher among boys than girls $(\mathrm{p}<0.001)$. The results showed that adolescents ate less breakfast with increase of their age $(\mathrm{p}=0.003)$ (Table 1$)$. Subjects whose fathers were office clerks had more breakfast consumption frequency compared with those whose fathers were self-employed $(\mathrm{p}=0.001)$. The results of subgroups' analysis revealed that subjects whose fathers were office clerks with higher levels of education ate more breakfast than the subjects whose fathers had lower levels $(\mathrm{p}=0.03)$. Similarly, students whose fathers were self-employed with higher levels of education had more breakfast frequency than those whose fathers were self-employed with lower levels $(\mathrm{p}=0.01)$. Although mothers' education level significantly affected breakfast consumption $(\mathrm{p}<0.001)$, no significant correlation was found between mothers' occupation and breakfast consumption $(\mathrm{p}=0.051)$. The results also indicate that $69.8 \%$ of subjects consume fast food at least once a week; $9.9 \%$ of adolescent boys and $9.8 \%$ of adolescent girls 
reported to eat fast foods more than three times a week. Among the demographic parameters, only fathers' occupation related to fast food consumption in adolescents $(\mathrm{p}=0.005)$ (Table 1$)$; however, no correlation was seen between other parameters and fast food consumption. In Table 2, factors associated with tendency to fast food consumption in adolescents was investigated. The questionnaire asks about adolescents and their families' interest in fast food consumption (If the individual and family members are interested in fast food consumption, answer Yesotherwise, answer NO) as well as how the proximity of the school and home to fast food stores is related to fast food consumption per week were evaluated. The effect of advertising on adolescents' tendency to consume fast food and interest in eating fast food in different situations was also questioned in the questionnaire (tendency to consume fast foods alone, with family or with friends). As seen in Table 2, several other factors are associated with adolescents' fast food consumption: adolescents' and families' interest $(\mathrm{p}<0.001)$, accompaniment of family and friends $(p=0.003)$, the effect of advertising on consumers $(p=0.038)$, and proximity of home $(p=0.043)$ and $s c h o o l(p=0.046)$ to fast food stores are also effective in the frequency of such foods' consumption (Table 2).

Table 1. The relation between Demographics factors and fast food $\&$ breakfast consumption in adolescents ( $\mathrm{n}=553$ )

\begin{tabular}{|c|c|c|c|c|c|}
\hline \multirow{2}{*}{\multicolumn{2}{|c|}{ Variables }} & \multicolumn{2}{|c|}{$\begin{array}{l}\text { Fast Food consumption } \\
(\text { days/week })(\mathrm{n}(\%))^{\mathrm{a}}\end{array}$} & \multicolumn{2}{|c|}{$\begin{array}{l}\text { Break Fast consumption } \\
\text { (days/week) }^{\mathrm{a}}\end{array}$} \\
\hline & & $\mathrm{n}(\%)$ & p-value ${ }^{*}$ & $\mathrm{n}(\%)$ & $p$-value \\
\hline \multirow{3}{*}{$\begin{array}{l}\text { Age of adolescents } \\
\text { (year) }\end{array}$} & $14-16$ & $305(55.6)$ & NS & $304(55.3)$ & 0.03 \\
\hline & $17-19$ & $244(44.4)$ & & $246(44.7)$ & \\
\hline & Mean \pm SD & $16.24 \pm 1.22$ & $\mathrm{NS}^{\mathrm{b}}$ & $16.24 \pm 1.22$ & $0.003^{\mathrm{b}}$ \\
\hline \multirow[t]{2}{*}{ Sex } & Male & $284(51.7)$ & NS & $284(51.6)$ & 0.000 \\
\hline & Female & $265(48.3)$ & & $266(48.4)$ & \\
\hline \multirow[t]{2}{*}{ Father's Education } & Nonacademic & $297(54.1)$ & NS & $299(54.4)$ & 0.000 \\
\hline & Academic & $252(45.9)$ & & $251(45.6)$ & \\
\hline \multirow[t]{2}{*}{ Mother's Education } & Nonacademic & $375(68.7)$ & NS & $377(68.9)$ & 0.000 \\
\hline & Academic & $171(31.3)$ & & $170(31.1)$ & \\
\hline \multirow[t]{3}{*}{ Father's Job } & Employee & $282(51.8)$ & 0.005 & $283(51.8)$ & 0.006 \\
\hline & Self employed & $218(40.1)$ & & $219(40.1)$ & \\
\hline & Other (Workers, farmers) & $44(8.1)$ & & $44(8.1)$ & \\
\hline \multirow[t]{2}{*}{ Mother's Job } & Housekeeper & $393(71.6)$ & NS & $395(71.8)$ & NS \\
\hline & Employee & $156(28.4)$ & & $155(28.2)$ & \\
\hline
\end{tabular}

a: Breakfast and fast food consumption was expressed as average number of days/week $(1=$ Never/Week, $2=1$ $2 \mathrm{x} /$ Week, $3=3-4 \mathrm{x} /$ Week, $4=5 \leq \mathrm{x} /$ Week); b: to investigate the relation between age with fast food and breakfast consumption using ANOVA test; NS: non-significant

Table 2. The effect of some relative factors on eating fast food in adolescents

\begin{tabular}{|c|c|c|c|c|c|c|c|}
\hline \multirow{2}{*}{\multicolumn{2}{|c|}{ Variables }} & \multicolumn{6}{|c|}{ Fast Food consumption (days/week) $(\mathrm{n}(\%))^{\mathrm{a}}$} \\
\hline & & $\mathrm{n}(\%)$ & Never/W & $1-2 / \mathrm{W}$ & $3-4 / \mathrm{W}$ & $5 \leq / W$ & $p$-value \\
\hline \multirow[t]{2}{*}{ Adolescents Interest } & Yes & $431(78.5)$ & $90(20.9)$ & $290(67.3)$ & $46(10.7)$ & $5(1.2)$ & $<0.001$ \\
\hline & No & $118(21.5)$ & $76(64.4)$ & $39(33.1)$ & $3(2.5)$ & $0(0)$ & \\
\hline \multirow[t]{2}{*}{ Family Interest } & Yes & $366(66.7)$ & $84(23)$ & $245(66.9)$ & $33(9)$ & $4(1.1)$ & $<0.001$ \\
\hline & No & $183(33.3)$ & $82(44.8)$ & $84(45.9)$ & $16(8.7)$ & $1(0.5)$ & \\
\hline \multirow[t]{3}{*}{ Accompaniment } & Only & $29(6.7)$ & $10(34.5)$ & $16(55.2)$ & $2(6.9)$ & $1(3.4)$ & 0.003 \\
\hline & Family & $231(53.2)$ & $89(38.5)$ & $128(55.4)$ & $12(5.2)$ & $2(0.9)$ & \\
\hline & Friends & $174(40.1)$ & $36(20.7)$ & $117(67.2)$ & $20(11.5)$ & $1(0.6)$ & \\
\hline \multirow[t]{2}{*}{ Advertisements } & Yes & $221(40.4)$ & $52(23.5)$ & $147(66.5)$ & $21(9.5)$ & $1(0.5)$ & 0.038 \\
\hline & No & $326(59.6)$ & $113(43.7)$ & $182(55.8)$ & $28(8.6)$ & $3(0.9)$ & \\
\hline \multirow{2}{*}{$\begin{array}{l}\text { Proximity of house to } \\
\text { fast food stores }\end{array}$} & Yes & $239(43.8)$ & $59(24.7)$ & $150(62.8)$ & $28(11.7)$ & $2(0.8)$ & 0.043 \\
\hline & No & $307(56.2)$ & $105(34.2)$ & $178(58)$ & $21(6.8)$ & $3(1)$ & \\
\hline \multirow{2}{*}{$\begin{array}{l}\text { Proximity of school to } \\
\text { fast food stores }\end{array}$} & Yes & $213(39.2)$ & $58(27.2)$ & $125(58.7)$ & $27(12.7)$ & $3(1.4)$ & 0.046 \\
\hline & No & $331(60.8)$ & $107(32.3)$ & $201(60.7)$ & $21(6.3)$ & $2(0.6)$ & \\
\hline
\end{tabular}

${ }^{a}$ Fast food consumption was expressed as average number of days/week $(1=$ Never/Week, 2= 1-2x/Week, 3= 3$4 \mathrm{x} /$ Week, $4=5 \leq \mathrm{x} /$ Week) 


\section{Discussion}

As already mentioned, two bad eating habits common among adolescents are the increase in fast foods consumption and the lack of eating breakfast, which are both associated with risk factors of metabolic syndromes including obesity, diabetes, and chronic diseases $(9,12,13)$. The present study also shows that more than two-thirds of the students have fast food at least once a week. Some other studies also point to the prevalence of fast food eating among adolescents (15). Lee revealed that almost $40 \%$ of high school students in Busan, Korea consume fast food 1-2 times a month (7). Larson et al. (11) found that $24 \%$ of boys and $20 \%$ of girls consume fast food more than 3 times a week, while in the present study, 9.9\% of boys and $8.9 \%$ of girls had fast food more than 3 times a week. Therefore, in this study, above statistics are lower compared with Larson's research, which is likely due to the traditional culture of the region and commitment to the family's traditional diet. This paper indicates a significant correlation between fast food consumption and exposure to advertisement, as does that of Andrea et al. (16). The results of a study showed that the availability or proximity of fast food stores to home or school is involved in the increased consumption of these foods (5). The present research came up with similar results: the consumption of fast food was higher by students whose home was located in proximity of fast food restaurants. A study suggests that students whose parents had higher education show more tendency to fast foods (17); in our study, however, parents' education did not affect their children's fast food consumption. In this research, breakfast consumption varied across gender: boys significantly surpassed girls in breakfast consumption. Such results confirm previous studies (18, 19). Researches show that weight control is the reason for less consumption of breakfast in female adolescents (20). In contrast, Aranceta (21) did not report any differences between boys and girl in breakfast consumption. In this study, $18.2 \%$ of students had breakfast 2 days a week or less, while it was reported to be $8 \%$ and $18 \%$ among Australian and British adolescents respectively (22). This paper showed that teenagers ate less breakfast with increasing age; Rampersaud, Verscan, and Pearson indicated similar results (14, 23, 24). Since teenagers seek more independence as they get older and parental control decreases, this change can be suggested as the reason for reduction in breakfast consumption; nevertheless, Hallstrom et al. (25) did not associate increasing age with such reduction. In addition, the results revealed that there is a significant correlation between fathers' educational level and children's breakfast consumption. Mullan et al. (22) report that demographic factors such as gender, race, and educational level play a role in the breakfast consumption. Other studies support the effects of demographic factors including parent's education on breakfast consumption by adolescents $(24,25)$. The present study also points out that mother's education correlated significantly with breakfast consumption during adolescence. Furthermore, Hallstrom et al. (25) found out that mothers' education level is effective in their daughters' breakfast consumption so that an increase in mothers' education level leads to regular breakfast consumption by daughters. Similar results were also reported in Europe $(18,26)$ and the US (20) confirming the results of this study. Although, some studies in Taiwan (27) and China (28) reject any links between parents' education level and adolescents' breakfast consumption, it seems that parents' high educational level leads to higher awareness which in turn, results in improving the quality of their children's diet, especially breakfast $(23,24,29)$. In the present study, fathers' occupation influenced adolescents' eating breakfast; those whose fathers were office clerks had more frequency in eating breakfast. Some studies have also linked parents' occupation with adolescents' eating breakfast (30). In this research, having breakfast did not correlate significantly with mothers' occupation while Keski-Rahkonen et al. (30), have reported the existence of such a relationship. Limitations of this study were: excluding family income as it was not possible to include it due to the selected age groups' unawareness about family income.

\section{Conclusions}

The present paper suggests that the prevalence of fast food eating and of breakfast skipping is high in Iranian adolescents. Breakfast consumption correlates significantly with adolescents' age and gender, as well as parents' occupation and educational level. So the present study indicated that, parents play a crucial role in shaping their children's eating habits. Considering the important role of family member's, especially the mother, about choosing adolescents' food and the effectiveness of the level of maternal education on students' knowledge and tendency to fast food consumption, more attention should be paid to improve mothers' knowledge, as an important strategy in reduction of fast food consumption in this age group. Performing an additional study on the role of nutritional education to parents to improve eating breakfast in adolescents from 14 to 18 years old with larger sample size and longitudinal method could be a suitable path for future research on this topic.

Acknowledgments:

This research was funded by Qazvin University of Medical Sciences. The authors would like to thank Dr. Hamed Mohammadi, Ms. Shiva Alimoradi and Ms. Shayda Alimoradi for assisting with the data collection. 


\section{Conflict of Interest:}

There is no conflict of interest to be declared.

\section{Authors' contributions:}

All authors contributed to this project and article equally. All authors read and approved the final manuscript.

\section{References:}

1) Bassett R, Chapman GE, Beagan BL. Autonomy and control: the co-construction of adolescent food choice. Appetite. 2008; 50(2-3): 325-32. doi: 10.1016/j.appet.2007.08.009. PMID: 17936413.

2) Condon EM, Crepinsek MK, Fox MK. School meals: types of foods offered to and consumed by children at lunch and breakfast. J Am Diet Assoc. 2009; 109(2 Suppl): S67-78. doi: 10.1016/j.jada.2008.10.062. PMID: 19166674.

3) Mirmiran P, Azadbakht L, Azizi F. Dietary quality-adherence to the dietary guidelines in Tehranian adolescents: Tehran Lipid and Glucose Study. Int J Vitam Nutr Res. 2005; 75(3): 195-200. doi: 10.1024/0300-9831.75.3.195. PMID: 16028635.

4) Lee SK, Novotny R, Daida YG, Vijayadeva V, Gittelsohn J. Dietary patterns of adolescent girls in Hawaii over a 2-year period. J Am Diet Assoc. 2007; 107(6): 956-61. doi: 10.1016/j.jada.2007.03.009. PMID: 17524716.

5) Chiang PH, Wahlqvist ML, Lee MS, Huang LY, Chen HH, Huang ST. Fast-food outlets and walkability in school neighbourhoods predict fatness in boys and height in girls: a Taiwanese population study. Public Health Nutr. 2011; 14(9): 1601-9. doi: 10.1017/S1368980011001042. PMID: 21729476.

6) Nasser K, Awartani F, Hasan J. Nutritional status in Palestinian schoolchildren living in West Bank and Gaza Strip: a cross-sectional survey. The Lancet. 2010.

7) JS L. A comparative study on fast food consumption patterns classified by age in Busan. Korean J Community Nutr. 2007; 12(5): 534-44.

8) Niemeier HM, Raynor HA, Lloyd-Richardson EE, Rogers ML, Wing RR. Fast food consumption and breakfast skipping: predictors of weight gain from adolescence to adulthood in a nationally representative sample. J Adolesc Health. 2006; 39(6): 842-9. doi: 10.1016/j.jadohealth.2006.07.001. PMID: 17116514.

9) Marlatt KL, Farbakhsh K, Dengel DR, Lytle LA. Breakfast and fast food consumption are associated with selected biomarkers in adolescents. Prev Med Rep. 2015; 3: 49-52. doi: 10.1016/j.pmedr.2015.11.014. PMID: 26844187, PMCID: 4733061.

10) Mirghafourvand M, Mohammad Alizadeh Charandabi S, Tavananezhad N, Karkhane M. Prevalence of abnormal body mass index in adolescents in the city of Sanandaj and its socio-demographic predictors. Journal of ilam university of medical sciences. 2014; 22(1): 119-29.

11) Larson NI, Neumark-Sztainer DR, Story MT, Wall MM, Harnack LJ, Eisenberg ME. Fast food intake: longitudinal trends during the transition to young adulthood and correlates of intake. J Adolesc Health. 2008; 43(1): 79-86. doi: 10.1016/j.jadohealth.2007.12.005. PMID: 18565441.

12) Nickle M, Pehrsson P. USDA updates nutrient values for fast food pizza. Procedia Food Science. 2013; 2 : 87-92. doi: 10.1016/j.profoo.2013.04.014.

13) Pereira MA, Kartashov AI, Ebbeling CB, Van Horn L, Slattery ML, Jacobs DR Jr, et al. Fast-food habits, weight gain, and insulin resistance (the CARDIA study): 15-year prospective analysis. Lancet. 2005; 365(9453): 36-42. doi: 10.1016/S0140-6736(04)17663-0. PMID: 15639678.

14) Rampersaud GC, Pereira MA, Girard BL, Adams J, Metzl JD. Breakfast habits, nutritional status, body weight, and academic performance in children and adolescents. J Am Diet Assoc. 2005; 105(5): 743-60. doi: 10.1016/j.jada.2005.02.007. PMID: 15883552.

15) Patterson R, Risby A, Chan MY. Consumption of takeaway and fast food in a deprived inner London Borough: are they associated with childhood obesity? BMJ Open. 2012; 2(3). pii: e000402. doi: 10.1136/bmjopen-2011-000402. PMID: 22721691, PMCID: 3383979.

16) Andreyeva T, Kelly IR, Harris JL. Exposure to food advertising on television: associations with children's fast food and soft drink consumption and obesity. Econ Hum Biol. 2011; 9(3): 221-33. doi: 10.1016/j.ehb.2011.02.004. PMID: 21439918.

17) Yarmohammadi P, Sharifirad G, Azadbakht L, Morovati Sharifabad MA, Hasanzadeh A. Examine the predictors of behavior among high school students on fast food consumption using the theory of planned behavior. Journal of Research in Health System. 2010; 7(4): 1-10.

18) Lien L. Is breakfast consumption related to mental distress and academic performance in adolescents? Public Health Nutrition. 2007; 10(4): 422-8. doi: 10.1017/S1368980007258550. PMID: 17362539. 
19) Matthys C, De Henauw S, Bellemans M, De Maeyer M, De Backer G. Breakfast habits affect overall nutrient profiles in adolescents. Public Health Nutr. 2007; 10(4): 413-21. doi: 10.1017/S1368980007248049. PMID: 17362538.

20) Timlin MT, Pereira MA, Story M, Neumark-Sztainer D. Breakfast eating and weight change in a 5-year prospective analysis of adolescents: Project EAT (Eating Among Teens). Pediatrics. 2008; 121(3): e638-45. doi: 10.1542/peds.2007-1035. PMID: 18310183.

21) Aranceta J, Serra-Majem L, Ribas L, Perez-Rodrigo C. Breakfast consumption in Spanish children and young people. Public Health Nutr. 2001; 4(6A): 1439-44. PMID: 11918497.

22) Mullan B, Wong C, Kothe E, O'Moore K, Pickles K, Sainsbury K. An examination of the demographic predictors of adolescent breakfast consumption, content, and context. BMC Public Health. 2014; $14: 264$. doi: 10.1186/1471-2458-14-264. PMID: 24645936, PMCID: 4000053.

23) Vereecken C, Dupuy M, Rasmussen M, Kelly C, Nansel TR, Al Sabbah H, et al. Breakfast consumption and its socio-demographic and lifestyle correlates in schoolchildren in 41 countries participating in the HBSC study. Int J Public Health. 2009; 54 Suppl 2: 180-90. doi: 10.1007/s00038-009-5409-5. PMID: 19639257, PMCID: 3408388.

24) Pearson N, Biddle SJ, Gorely T. Family correlates of breakfast consumption among children and adolescents. A systematic review. Appetite. 2009; 52(1): 1-7. doi: 10.1016/j.appet.2008.08.006. PMID: 18789364.

25) Hallstrom L, Vereecken CA, Ruiz JR, Patterson E, Gilbert CC, Catasta G, et al. Breakfast habits and factors influencing food choices at breakfast in relation to socio-demographic and family factors among European adolescents. The HELENA Study. Appetite. 2011; 56(3): 649-57. doi: 10.1016/j.appet.2011.02.019. PMID: 21376767.

26) Pearson N, MacFarlane A, Crawford D, Biddle SJ. Family circumstance and adolescent dietary behaviours. Appetite. 2009; 52(3): 668-74. doi: 10.1016/j.appet.2009.03.004. PMID: 19501765.

27) Yang RJ, Wang EK, Hsieh YS, Chen MY. Irregular breakfast eating and health status among adolescents in Taiwan. BMC Public Health. 2006; 6: 295. doi: 10.1186/1471-2458-6-295. PMID: 17150112, PMCID: 1764735.

28) Shi Z, Lien N, Kumar BN, Holmboe-Ottesen G. Socio-demographic differences in food habits and preferences of school adolescents in Jiangsu Province, China. Eur J Clin Nutr. 2005; 59(12): 1439-48. doi: 10.1038/sj.ejcn.1602259. PMID: 16118652.

29) Szajewska H, Ruszczynski M. Systematic review demonstrating that breakfast consumption influences body weight outcomes in children and adolescents in Europe. Crit Rev Food Sci Nutr. 2010; 50(2): 113-9. doi: 10.1080/10408390903467514. PMID: 20112153.

30) Keski-Rahkonen A, Kaprio J, Rissanen A, Virkkunen M, Rose RJ. Breakfast skipping and healthcompromising behaviors in adolescents and adults. Eur J Clin Nutr. 2003; 57(7): 842-53. doi: 10.1038/sj.ejcn.1601618. PMID: 12821884. 